\title{
Intravenous thrombolysis and endovascular thrombectomy in elderly individuals with acute ischemic stroke
}

\section{Authors:}

\section{Michelle Lin, MD}

Cerebrovascular Fellow, Division of

Cerebrovascular Disease, Department

of Neurology, Johns Hopkins

University School of Medicine,

Baltimore, MD.

Email: mlin54@jhmi.edu

\section{Robert Wityk, MD}

Associate Professor of Neurology,

Emeritus, Division of

Cerebrovascular Disease, Department

of Neurology, Johns Hopkins

University School of Medicine,

Baltimore, MD.

Email: rwityk@jhmi.edu

\begin{abstract}
:
Very elderly (age $\geq 80$ yo) individuals account for about one-third of all stroke admissions, but the risks and benefits of intravenous thrombolysis (IV-tPA) and endovascular thrombectomy (EVT) in this growing population remain unclear. Thrombolysis is generally used less often for elderly individuals in the United States than younger age groups, likely due to the potential for worse outcomes in comparison. Very elderly individuals were under-represented in early thrombolysis trials, yet contemporary reperfusion trials, as well as meta-analysis, included a greater proportion of very elderly individuals. Pooled analyses from current reperfusion trials suggest that IV-tPA and EVT are safe and effective therapies for very elderly individuals presenting with acute ischemic stroke. Future prospective studies are needed to further assess the safety and effectiveness of acute reperfusion in this growing population. In this review, we examined agerelated differences in clinical outcomes for acute ischemic stroke therapies.
\end{abstract}




\section{Introduction}

People older than 80 years of age represent the fastest growing segment of the population in developed countries, and account for more than a third of stroke admissions. While intravenous tissue plasminogen activator (IV-tPA) and endovascular thrombectomy (EVT) have Class 1 level of evidence for the treatment of acute ischemic stroke, ${ }^{1,2}$ the debate continues about the use of thrombolysis in older patients given concerns for age-related tissue and functional fragility. In this review article, we will discuss the safety and effectiveness of IV-tPA and EVT in elderly individuals with acute ischemic stroke.

\section{Thrombolytic Therapy}

The NINDS trial for acute ischemic stroke found that the use of IV-tPA within 3 hours of stroke onset resulted in better functional outcome at 3 months than placebo, even though the rate of symptomatic intracranial hemorrhage was slightly higher. ${ }^{1,3}$ The trial did not have an upper age limit to exclude patients, but there is little data concerning the safety and effectiveness of thrombolysis for stroke in the elderly (age $>80$ made up $4 \%$ of subjects in the NINDS $\mathrm{A}$ and $13 \%$ of subjects in the NINDS B cohorts). Post-hoc analysis of the results found poorer outcome with increasing age. In multivariate analysis, the combination of increasing age and increasing deficit severity was independently associated with poorer outcome; however, this factor was not associated with the likelihood of a favorable response to IV-tPA. ${ }^{3}$ ECASS III trial later supported the use of IV-tPA between 3 and 4.5 hours but had an upper age limit to 80 years. ${ }^{4}$ Nevertheless, a recent pooled analysis of nine randomized trials, with $26 \%$ participants aged 80 years or above, demonstrated improved functional outcome at 3 months than placebo for a delay in treatment extending to 4.5 hours after stroke onset, with a greater benefit with earlier treatment. ${ }^{5}$ Current American Heart Association guidelines do not indicate an age limit for the use of thrombolytic therapy in acute stroke. $^{2}$

While robust data support the use of intravenous thrombolysis in patients younger than 80 years of age within 4.5 hours of stroke onset, older people are underrepresented in stroke thrombolysis trials. ${ }^{5}$ The International Stroke Trial (IST-3), to the best of our knowledge, is one of the largest, randomized thrombolysis trials with more than half of the patients $(53 \%)$ were older than 80 years of age to evaluate the benefits and harms of IV-tPA in extended window up to 6 hours of stroke onset. ${ }^{6}$ There were more fatal or sICH within 7 days in the treatment group than the placebo group ( $7 \%$ vs $1 \%$ ). However, by 6 months of follow-up, there was evidence that IV-tPA improved functional outcome in all patients (OR 1.26, 95\% CI 1.04-1.53, $\mathrm{P}=0.018){ }^{7} \quad$ Treatment appeared at least as effective in elderly group (age $\geq 80$ ) as in younger patients. In subgroup analyses, there were significant trends towards larger beneficial effects of treatment in 1) elderly, 2) more severe strokes, 3) treatment within 3 hours of stroke onset. Adjusted odds ratio (OR) of good functional outcome at 6 months comparing IV-tPA vs placebo among elderly was 1.35 (95\% confidence interval [CI] 0.97-1.88), whereas the OR for the younger group was 0.92 (95\% CI 0.67-1.26), with a statistically significant difference between these ORs $(\mathrm{p}=0.029)^{7}$

Given the continuing uncertainty on the use of IV-tPA in elderly individuals presenting with acute ischemic stroke, Emberson $\mathrm{J}$, et al conducted an individuallevel meta-analysis from nine randomized 
control thrombolysis trials to assess the effect of age, treatment delay, and stroke severity on the effects of IV-tPA for acute ischemic stroke. ${ }^{8}$ The study included 6,756 patients ( $26 \%$ were elderly, 80 years or above), defined good stroke outcome as no significant disability at 3-6 months (modified Rankin Score of 0 or 1) and defined sICH within 7 days using the SITS-MOST definition. Authors found that IV-tPA significantly increased the odds of a good outcome, with earlier treatment resulting in significantly greater proportional benefit ( $p=0.016$ for trend of increasing proportional benefit with earlier treatment). Importantly, age did not change the effect of IV-tPA on odds of a good outcome $(\mathrm{p}=0.53)$. The effect of IV-tPA was similar for patients aged 80 years or younger $(39 \%$ vs $34 \%$, OR 1.25 , $95 \%$ CI $1.10-1.42, \mathrm{p}<0.0001)$ and for those older than 80 years (18\% vs $13 \%$, OR 1.56 , 95\% CI 1.17-2.08, $\mathrm{p}=0.0023$ ).

As for safety, IV-tPA increased the likelihood of sICH. Incidence of type 2 parenchymal hemorrhage within 7 days was $6.8 \%$ vs $1.3 \%$ in IV-tPA vs control group (OR 5.55, 95\% CI 4.01-7.70; p<0.0001). However, there was no age-related difference in the incidence of fatal sICH within 7 days; patients above or below the age of 80 years have similar incidence of fatal sICH $(3.6 \%$ vs $2.3 \%){ }^{8}$ Taken together, therefore, despite an average absolute increased risk of early death from intracranial hemorrhage of about $2 \%$, by 3-6 months this risk was offset by an average absolute increase in disability-free survival of about $10 \%$ for patients treated within 3.0 hours and about $5 \%$ for patients treated after 3.0 hours, up to 4.5 hours. $^{8}$ This individual-data meta-analysis of thrombolysis trial demonstrated that irrespective of age or stroke severity, and despite an increased risk of fatal intracranial hemorrhage during the first few days after treatment, IV-tPA significantly improves the overall odds of a good stroke outcome when delivered within $4.5 \mathrm{~h}$ of stroke onset, with earlier treatment associated with bigger proportional benefits.

Given the increasing age in the population and the increased stroke risk in the elderly, thrombolytic therapy may intuitively become more commonly used in elderly patients. Indeed, the Get With the Guideline (GWTG-stroke) registry from 2003-2001 involving 1,093,895 acute ischemic stroke admissions showed a near doubling of absolute rate of IV-tPA administration within 3 hours of stroke onset from $4.0 \%$ in $2003-2005$ to $7.0 \%$ in 2010 2011. ${ }^{9}$ This substantial improvement may be attributable in part to a decade of national efforts in stroke quality improvement targeting hospital-based processes. ${ }^{10}$ Similar increases in the rate of intravenous tPA use have been reported in administrative registry such as the Nationwide Inpatient Sample in the United States from 2000 to 2010 across all age groups. The magnitude of increase was the greatest in very elderly individuals age 80 or older with the rate of increase of 1.25 (1.25-1.26) compared to other age groups 1.15 (1.15-1.16) for age 18-64yo, and $1.17(1.17-1.18)$ for age $65-79$ yo. ${ }^{11}$

\section{Endovascular Thrombectomy}

In addition to IV-tPA, five randomized trials published in 2015 demonstrated the safety and effectiveness of endovascular thrombectomy (EVT) for the treatment of large-vessel occlusive ischemic stroke within 6 hours of symptom onset. ${ }^{12-16}$ The HERMES study was a meta-analysis of individual patient data from the five randomized trials. ${ }^{17}$ The analysis included 1287 patients randomized to receive EVT vs standard of treatment (i.e. IV-tPA). Mechanical thrombectomy significantly reduced disability at 90 days compared with control 
(OR 2.5, 95\% CI 1.76-3.53; $\mathrm{p}<0.0001)$. The number needed to treat with EVT to reduce disability was 2.6. In subgroup analysis by age, authors showed no difference in outcome suggesting that EVT is effective in very elderly individuals aged 80 years or older (OR 3.68, 95\% CI 1.95-6.92 as compared to OR $2.44,95 \%$ CI $1.70-3.50) .{ }^{17}$ Mortality at 90 days and sICH did not differ between groups. ${ }^{17}$

\section{Conclusion}

Older age continued to be a common exclusion criterion in contemporary clinical trials assessing acute reperfusion therapy.
Indeed 3 of the 6 recent randomizedcontrolled trials comparing EVT and IV-tPA had an upper age limit of 80yo (SWIFTPRIME, REVASCAT, THRACE). Nevertheless, pooled data from meta-analysis of high-quality randomized control trials for thrombolysis and EVT support the use of IVtPA within 4.5 hours of stroke onset, and EVT within 6 hours of stroke onset in elderly individuals above the age of 80 years without significant increase in sICH compared to younger individuals. While the population burden of stroke associated with ageing is rapidly rising, there is clearly a need for prospective trials looking for the optimal acute reperfusion therapy options for elderly individuals. 


\section{References}

1. Jauch EC, Saver JL, Adams HP, Jr., Bruno A, Connors JJ, Demaerschalk $\mathrm{BM}$, et al. Guidelines for the early management of patients with acute ischemic stroke: A guideline for healthcare professionals from the american heart association/american stroke association. Stroke; a journal of cerebral circulation. 2013;44:870-947

2. Powers WJ, Derdeyn CP, Biller J, Coffey CS, Hoh BL, Jauch EC, et al. 2015 american heart association/american stroke association focused update of the 2013 guidelines for the early management of patients with acute ischemic stroke regarding endovascular treatment: A guideline for healthcare professionals from the american heart association/american stroke association. Stroke; a journal of cerebral circulation. 2015;46:30203035

3. Tissue plasminogen activator for acute ischemic stroke. The national institute of neurological disorders and stroke rtpa stroke study group. The New England journal of medicine. 1995;333:1581-1587

4. Hacke W, Kaste M, Bluhmki E, Brozman M, Davalos A, Guidetti D, et al. Thrombolysis with alteplase 3 to 4.5 hours after acute ischemic stroke. The New England journal of medicine. 2008;359:1317-1329

5. Lees KR, Emberson J, Blackwell L, Bluhmki E, Davis SM, Donnan GA, et al. Effects of alteplase for acute stroke on the distribution of functional outcomes: A pooled analysis of 9 trials. Stroke; a journal of cerebral circulation. 2016;47:2373-2379

6. Arauz A, Berge E, Sandercock P. Third international stroke trial 3: An update. Curr Opin Neurol. 2014;27:812

7. Sandercock P, Wardlaw JM, Lindley RI, Dennis M, Cohen G, Murray G, et al. The benefits and harms of intravenous thrombolysis with recombinant tissue plasminogen activator within $6 \mathrm{~h}$ of acute ischaemic stroke (the third international stroke trial [ist-3]): A randomised controlled trial. Lancet (London, England). 2012;379:2352-2363

8. Emberson J, Lees KR, Lyden P, Blackwell L, Albers G, Bluhmki E, et al. Effect of treatment delay, age, and stroke severity on the effects of intravenous thrombolysis with alteplase for acute ischaemic stroke: A meta-analysis of individual patient data from randomised trials. Lancet (London, England). 2014;384:19291935

9. Schwamm LH, Ali SF, Reeves MJ, Smith EE, Saver JL, Messe S, et al. Temporal trends in patient characteristics and treatment with intravenous thrombolysis among acute ischemic stroke patients at get with the guidelines-stroke hospitals. Circ Cardiovasc Qual Outcomes. 2013;6:543-549

10. Schwamm L, Fayad P, Acker JE, 3rd, Duncan P, Fonarow GC, Girgus M, et al. Translating evidence into practice: A decade of efforts by the american heart association/american stroke 
Medical Research Archives, Vol. 5, Issue 6, June 2017

Intravenous thrombolysis and endovascular thrombectomy in elderly individuals with acute ischemic stroke

association to reduce death and disability due to stroke: A presidential advisory from the american heart association/american stroke association. Stroke; a journal of cerebral circulation. 2010;41:10511065

11. Lin MP CS, Towfighi A, Kim-Tenser M, Mack WJ, Sanossian N. Temporal trends in tpa administration among very elderly hospitalized with ischemic stroke in the united states. Stroke; $a$ journal of cerebral circulation. 2015;46:A158

12. Berkhemer OA, Fransen PS, Beumer $\mathrm{D}$, van den Berg LA, Lingsma HF, Yoo AJ, et al. A randomized trial of intraarterial treatment for acute ischemic stroke. The New England journal of medicine. 2015;372:11-20

13. Goyal M, Demchuk AM, Menon BK, Eesa M, Rempel JL, Thornton J, et al. Randomized assessment of rapid endovascular treatment of ischemic stroke. The New England journal of medicine. 2015;372:1019-1030
14. Campbell BC, Mitchell PJ, Kleinig TJ, Dewey HM, Churilov L, Yassi N, et al. Endovascular therapy for ischemic stroke with perfusion-imaging selection. The New England journal of medicine. 2015;372:1009-1018

15. Saver JL, Goyal M, Bonafe A, Diener HC, Levy EI, Pereira VM, et al. Stentretriever thrombectomy after intravenous t-pa vs. T-pa alone in stroke. The New England journal of medicine. 2015;372:2285-2295

16. Jovin TG, Chamorro A, Cobo E, de Miquel MA, Molina CA, Rovira A, et al. Thrombectomy within 8 hours after symptom onset in ischemic stroke. The New England journal of medicine. 2015;372:2296-2306

17. Goyal M, Menon BK, van Zwam WH, Dippel DW, Mitchell PJ, Demchuk AM, et al. Endovascular thrombectomy after large-vessel ischaemic stroke: A meta-analysis of individual patient data from five randomised trials. Lancet (London, England). 2016;387:1723-1731 